\title{
Ações recomendadas para prevenção da transmissão vertical do HIV
}

\author{
Abilene do N. Gouvêa ${ }^{1^{\star}}$
}

\section{Resumo}

O progressivo aumento do número de casos de AIDS entre as mulheres e, consequentemente, da transmissão vertical do HIV vem assumindo grande importância epidemiológica, recebendo atenção especial com a implementação das recomendações do Ministério da Saúde para a profilaxia da transmissão vertical do HIV e terapia antirretroviral em gestantes. O objetivo desta revisão é apresentar as principais ações obstétricas para a profilaxia da transmissão vertical do HIV, contribuindo para divulgação das recomendações brasileiras e consequentemente para a redução das taxas de transmissão vertical do HIV. A transmissão vertical do HIV ocorre por meio da passagem do vírus da mãe para o bebê durante a gestação (35\%), parto (65\%) e o risco acrescido através da amamentação entre 7\% e $22 \%$ por exposição. A literatura mostra uma redução dessa taxa para níveis entre $1 \%$ e $2 \%$ com a aplicação de todas as intervenções preconizadas pelo Ministério da Saúde, que são atualizadas e baseadas nas melhores evidências científicas disponíveis. Porém, apesar dos esforços direcionados para o desenvolvimento das ações e fornecimento de insumos, os dados referentes à monitorização das etapas de intervenção para a profilaxia da transmissão vertical do HIV sugerem diversas falhas no processo e o não cumprimento das recomendações, o que reforça a necessidade de divulgação das recomendações existentes. A realização das condutas padronizadas contribui significativamente para a redução da transmissão do HIV da mãe para o feto na quase totalidade dos casos. O conjunto das ações recomendadas e o uso adequado dos insumos disponíveis são a base para a atuação profissional ética e competente. Esta revisão espera contribuir para a melhoria da qualidade na atenção às mulheres na gestação, parto e puerpério e ao seu recém-nascido, resultando na redução das taxas de transmissão vertical do HIV.

Descritores: Saúde da mulher; Transmissão vertical de doença infecciosa; Gravidez; HIV.

\section{Abstract \\ Recommended actions for prevention of vertical transmission of HIV}

The progressive increase in the number of AIDS cases among women and, consequently, vertical transmission of HIV has been taking a great epidemiological importance, getting special attention with the implementation of the recommendations of the Ministry of Health for the prevention of vertical transmission of HIV and antiretroviral therapy in pregnant women. The purpose of this review is to present the main
1. Núcleo Perinatal. Hospital Universitário Pedro Ernesto.

Universidade do Estado do Rio de Janeiro. Rio de Janeiro, RJ, Brasil.

"Endereço para correspondência:

Rua Pedro Aleixo, 92, lote 8, casa 1

Rio de Janeiro, RJ. CEP: 22723-475.

E-mail: abilenegouvea@uol.com.br

Revista HUPE, Rio de Janeiro, 2015;14(2):78-86

doi: $10.12957 /$ rhupe.2015.18443

Recebido em 06/10/2014. Aprovado em 25/01/2015.

obstetric actions for the prevention of vertical transmission of HIV, helping to disseminate the Brazilian recommendations and, consequently, to reduce vertical HIV transmission rates. The vertical transmission of HIV occurs through the passage of the virus from the mother to the baby during pregnancy (35\%), delivery (65\%) and the increased risk through breastfeeding between $7 \%$ and $22 \%$ by exposure. Literature shows a reduction in that rate to levels between $1 \%$ to $2 \%$ with the application of all interventions recommended by the Ministry of Health, which are updated and based on the best scientific evidences available. However, despite the efforts towards the development of actions and provision of inputs, the data for the monitoring of intervention steps to prevent vertical transmission of HIV suggest several flaws in the process and non-compliance with the recommendations, reinforcing the need for dissemination of existing recommendations. The implementation of standard approaches significantly contributes to the reduction of HIV transmission from the mother to the fetus, in almost all cases. The set of recommended actions and the appropriate use of the available inputs are the basis for ethical and competent professional participation. It is this review's intention to contribute for the improvement of women's attention during pregnancy, childbirth and puerperium and to your newborn, resulting in the reduction of HIV vertical transmission rates.

Keywords: Women's health; Vertical transmission of infectious disease; Pregnancy; HIV.

\section{Resumen}

\section{Medidas recomendadas para la prevención de la transmisión vertical del VIH}

El aumento progresivo en el número de casos de SIDA entre las mujeres $\mathrm{y}$, por consiguiente, la transmisión vertical del 
VIH está cobrando mayor importancia epidemiológica, recibiendo atención especial con la implementación de las recomendaciones del Ministerio de Salud para la profilaxis de la transmisión vertical del VIH y la terapia antirretroviral en mujeres embarazadas. El objetivo de esta revisión es presentar las principales acciones obstétricas para la profilaxis de la transmisión vertical del VIH, contribuyendo en la difusión de las recomendaciones brasileras y, en consecuencia en la reducción de las tasas de transmisión vertical del VIH. La transmisión vertical del VIH se produce a través del paso del virus de la madre para el bebé durante el embarazo (35\%), parto (65\%) y el aumento del riesgo a través de la lactancia entre el $7 \%$ y el $22 \%$ por exposición. La literatura muestra una reducción de esta tasa para niveles entre el $1 \%$ y el $2 \%$ con la aplicación de todas las intervenciones recomendadas por el Ministerio de Salud, que se actualizan y basan en las mejores evidencias científicas disponibles. Sin embargo, a pesar de los esfuerzos dirigidos al

\section{Introdução}

Após três anos do surgimento do primeiro caso de síndrome da imunodeficiência adquirida (AIDS) no Brasil, em 1983, iniciou-se o modelo de atenção que consolidou em 1986 o Programa Brasileiro de DST/AIDS. Atualmente, a política fundamentada na premissa de que a prevenção e a assistência da sociedade civil e do Estado não podem estar dissociadas obteve um avanço significativo e reconhecimento mundial a partir da metade da década de $90.1,2,3$

A taxa de transmissão vertical do vírus da imunodeficiência humana (HIV), quando não há intervenção de profilaxia, gira em torno de $20 \%$, enquanto com a utilização combinada de intervenções, pode ser reduzida para cifras menores que $1 \%$., $, 5,6$

Alguns estudos têm baseado as recomendações do Ministério da Saúde (MS) e demonstraram como principais fatores contribuintes para a redução da transmissão vertical do HIV a promoção de intervenções de profilaxia que reduzam a carga viral materna e que propiciem a realização do parto com adequada assistência ao binômio mãe-filho. Todos os encontros com a gestante, parturiente ou puérpera representam oportunidades para o oferecimento do teste anti-HIV e início da terapia antirretroviral. ${ }^{7}$ As crianças de nosso país não podem ter como herança a AIDS, principalmente se considerarmos que as recomendações para a profilaxia da transmissão vertical são altamente eficazes e estão amplamente disponíveis no Sistema Único de Saúde (SUS).

OComitê Assessor para Recomendações de Profilaxia da Transmissão Vertical do HIV e Terapia Antirretroviral em Gestantes (TARV) tem sido responsável por desarrollo de las medidas y el suministro de insumos, los datos referentes a la monitorización de las etapas de intervención para la profilaxis de la transmisión vertical del VIH sugieren varias fallas en el proceso y el cumplimiento de las recomendaciones, lo que refuerza la necesidad de divulgación de las recomendaciones. Realizar conductas estándares contribuye significativamente en la reducción de la transmisión del VIH de la madre al feto, en la casi totalidad de casos. El conjunto de acciones recomendadas y el uso adecuado de los insumos disponibles son la base para la actuación profesional ética y competente. Esta revisión espera contribuir a mejorar la calidad de la atención a las mujeres y al recién nacido durante el embarazo, parto y puerperio, lo que resulta en la reducción de las tasas de transmisión vertical del VIH.

Palabras clave: Salud de la mujer; Transmisión vertical de enfermedad infecciosa; Embarazo; VIH.

revisar as recomendações de terapia antirretroviral e as demais condutas relacionadas à profilaxia da transmissão vertical do HIV, considerando sempre as condições de implementação das recomendações no SUS e baseadas nas melhores evidências científicas disponíveis e que serão descritas a seguir. ${ }^{8}$

\section{Aconselhamento em DST/AIDS e a prevenção da transmissão vertical}

O aconselhamento é um processo que consiste na escuta ativa, individualizada, centrada na pessoa, que possibilita o estabelecimento de uma relação de confiança entre a mulher e o profissional de saúde. Tem como finalidade promover a troca de informações entre ambos, de modo a permitir ao profissional de saúde, estimar a possibilidade para a mulher e seu parceiro, de ter havido ou haver situações de exposição ao risco de infecção pelo HIV e outras doenças sexualmente transmissíveis (DSTs). ${ }^{8,9,10}$

\section{Aconselhamento pré-teste anti-HIV}

O aconselhamento não se limita à oferta e a solicitar o consentimento para a testagem. Propõe-se promover que a mulher construa suas alternativas individuais e coletivas visando a proteção e cuidado, baseado na revisão de crenças, representações, condições de vulnerabilidade, aproximando, assim, a mulher dos serviços de saúde.

As unidades de saúde podem facilitar o processo de aconselhamento através da realização de grupos informativos e outros meios de informação para as gestantes e seus familiares. ${ }^{8,9,10}$ 


\section{Aconselhamento pós-teste anti-HIV}

O profissional de saúde deverá reforçar e discutir com a mulher o significado do resultado de seu teste e, independentemente do resultado, dar informações precisas e pertinentes à clientela, reforçando as informações sobre o modo de transmissão do HIV e outras DSTs e sobre as medidas de prevenção primária ou de prevenção de reinfecção. ${ }^{8,9,10}$

\section{Diante de resultado negativo}

O resultado do exame poderá significar que a mulher não está infectada e/ou que foi infectada tão recentemente que não houve tempo para seu organismo produzir anticorpos em quantidade que possa ser detectada pelo teste utilizado. Nesses casos, com base nas informações colhidas durante o processo de aconselhamento pré-teste, a necessidade de um novo teste poderá ser considerada pelo profissional de saúde, ou seja, as informações apontarão, ou não, para a possibilidade de a mulher se encontrar em período de "janela imunológica". ${ }^{8,9,10}$

\section{Diante de resultado indeterminado}

Poderá significar um falso-positivo ou um verdadeiro-positivo de uma infecção recente, cujos anticorpos anti-HIV circulantes não estão ainda em quantidade suficiente para serem detectáveis pelo teste. Nessa situação, o teste deverá ser repetido no período de tempo que será definido pelo laboratório, orientando a mulher e seu parceiro para o uso de preservativo em todas as relações sexuais. $8,9,10$

\section{Diante de resultado positivo}

Ao comunicar esse resultado, o profissional de saúde deverá estar atento às reações aparentes e sutis da mulher, oferecendo o tempo necessário para que o impacto do diagnóstico seja assimilado e seus sentimentos sejam expressos. É importante reforçar a ideia de que estar infectada pelo HIV não significa portar a AIDS, que existem remédios que controlam a infecção e reduzem a possibilidade de transmissão para o bebê, devendo, para isso, ser adequadamente avaliada e medicada por um profissional especializado na assistência de pessoas portadoras do HIV. ${ }^{8,9,10}$

O profissional de saúde deve lembrar o caráter confidencial do teste anti-HIV, e somente após a sinalização pela mulher e escolha da pessoa com que deverá compartilhar desse diagnóstico, oferecerá o apoio que se fizer necessário nesse processo. ${ }^{11}$

\section{Diagnóstico da infecção pelo HIV}

O conhecimento precoce do estado sorológico da infecção pelo HIV torna possível a adoção de medidas que reduzem substancialmente o risco de transmissão vertical do HIV. A testagem e o aconselhamento são essenciais e integram o cuidado no pré-natal, que preconiza a testagem no primeiro trimestre ou na primeira consulta pré-natal, repetindo-a no terceiro trimestre. Resguardando o sigilo e registrando no prontuário que tais medidas foram adotadas, bem como o consentimento ou a negativa da gestante em realizar o exame. ${ }^{8,9,11}$

\section{Diagnóstico laboratorial da infecção pelo HIV}

Os métodos laboratoriais têm sido aprimorados e os kits comerciais para detecção da infecção pelo HIV evoluíram consideravelmente, permitindo reduzir o período de janela imunológica e aumentando a capacidade para detectar o HIV-1 e HIV-2, além de vários subtipos.

Periodicamente, o MS atualiza e aperfeiçoa o algoritmo de testagem para o diagnóstico da infecção pelo HIV, conforme explicitado nas figuras 1 e 2.,12

\section{Avaliação laboratorial inicial}

A abordagem laboratorial no início do acompanhamento clínico obstétrico de gestantes infectadas pelo HIV tem como objetivo avaliar a condição geral de saúde da mulher, identificar a presença de morbidades e outros fatores que possam interferir na evolução da gravidez ou da infecção pelo HIV, além de avaliar a situação imunológica e virologia inicial.

A contagem de LT-CD4 $4^{+}$estabelece o risco de progressão para AIDS e óbito, sendo, portanto, o indicador laboratorial mais importante em pessoas assintomáticas. Para adultos em geral, a carga viral (CV) assume maior relevância quando a contagem de LT-CD4 ${ }^{+}$ estiver próxima a 350 por $\mathrm{mm}^{3}$, auxiliando a estimar a potencial intensidade da deterioração imunológica futura. A CV é um dos fatores associados ao risco de transmissão vertical do HIV e auxilia na definição da via de parto. A carga viral é utilizada para monitoramento da gestante infectada pelo HIV, auxiliando a avaliação da resposta ao tratamento antirretroviral.Em gestantes 
Figura 1. Fluxograma mínimo para o diagnóstico laboratorial da infecção pelo HIV em indivíduos com idade acima de 18 meses.

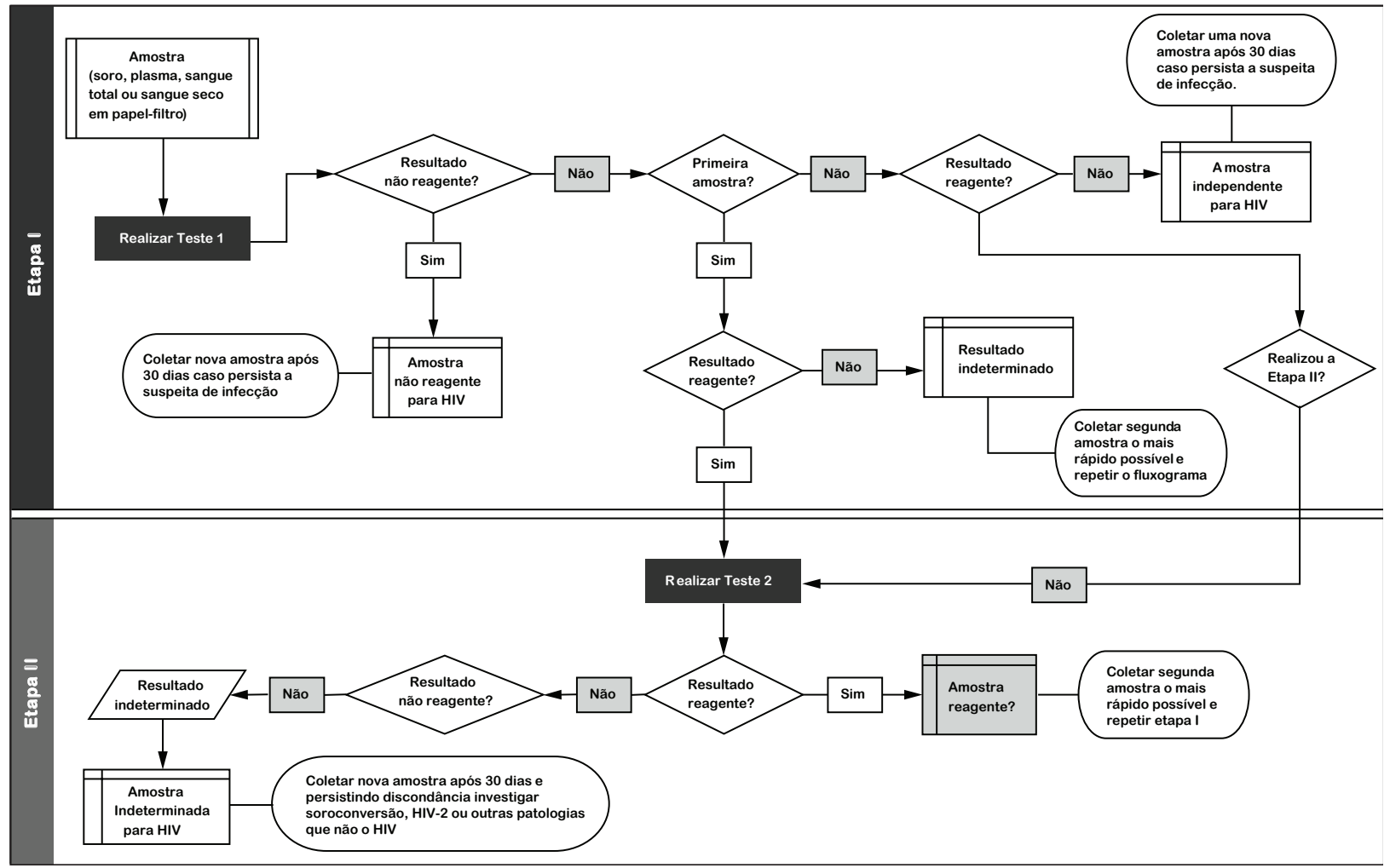

Fonte: Ministério da Saúde, 2010.

Legenda: $\square \longrightarrow$ Processo predefinido $\rightarrow$ Processo

$\longrightarrow$ Exige tomada de decisão $\longrightarrow$ Finalizador

Figura 2. Fluxograma para o diagnóstico rápido da infecção pelo HIV em situações especiais.

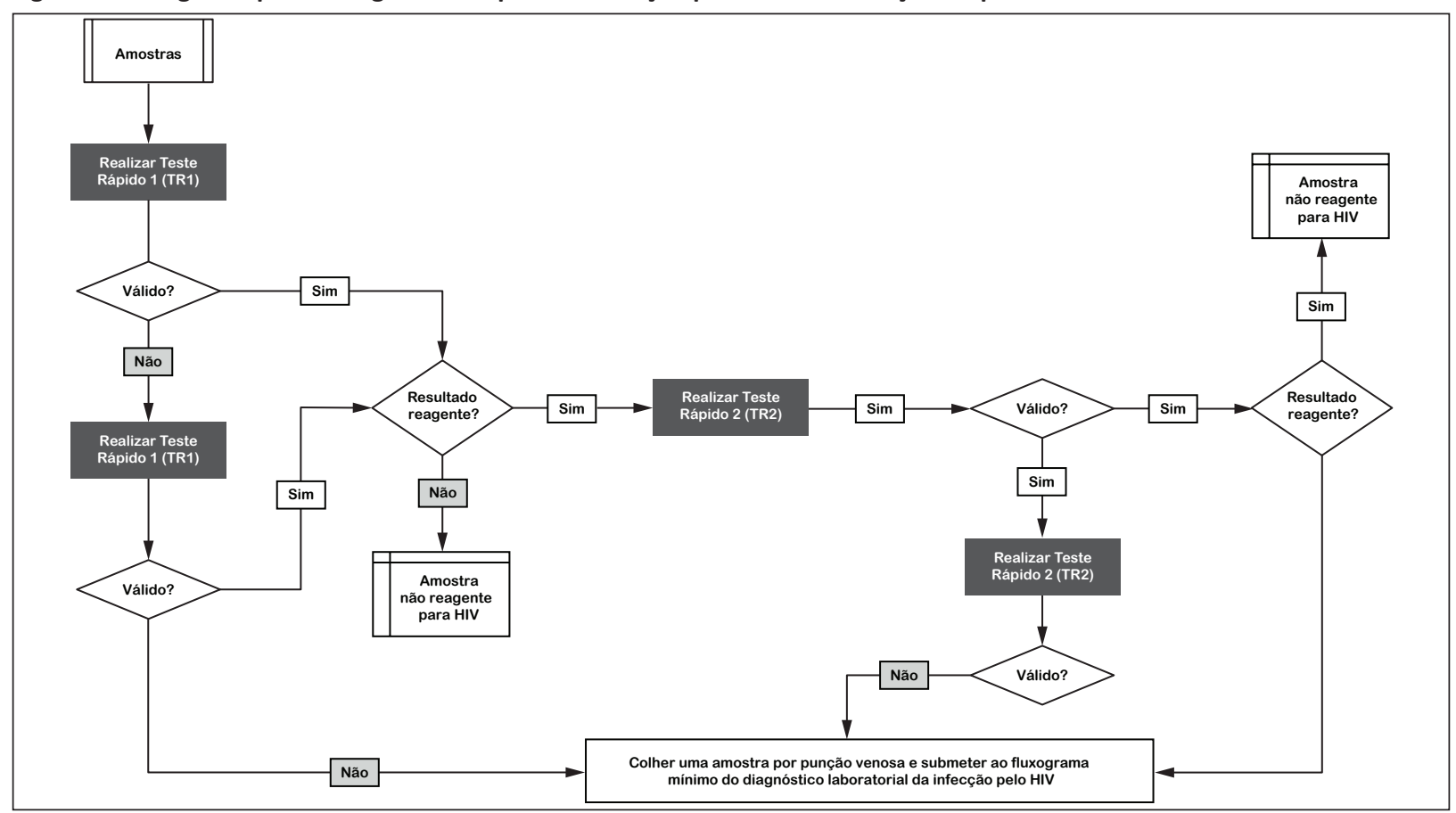

Fonte: Ministério da Saúde, 2010. 


\section{Artigo de revisão}

que já se apresentam com dano imunológico ao diagnóstico, a elevação da contagem de LT-CD4 ${ }^{+}$previne o desenvolvimento de manifestações oportunistas, sendo este um dos objetivos do tratamento. ${ }^{8}$

\section{Periodicidade de repetição de exames durante a gestação}

A tabela 1 indica os exames sugeridos para estruturar a abordagem laboratorial inicial e a frequência da sua realização durante o pré-natal. ${ }^{8}$

\section{Manejo antirretroviral na gestação}

Devido à sua potência de inibição da replicação viral, menor risco de resistência viral em curto prazo e maior segurança dos antirretrovirais, a TARV deve ser administrada a todas as gestantes infectadas pelo HIV, com associação de três antirretrovirais, independentemente da situação virológica, clínica ou imunológica.

Tabela 1. Periodicidade de repetição de exames durante a gestação.

\begin{tabular}{|c|c|c|c|}
\hline Exame & Inicial & Peridiocidade & Comentários \\
\hline Hemograma & $\operatorname{Sim}$ & $\begin{array}{l}\text { Repetir ao redor } \\
\text { de } 30 \text { semanas }\end{array}$ & \\
\hline Tipagem sanguínea & Sim & & \\
\hline Coombs indireto & Sim & $\begin{array}{l}\text { Se o resultado for negativo repetir } \\
\text { em torno da } 30^{a} \text { semana e após } \\
\text { mensamente }^{1}\end{array}$ & $\begin{array}{l}\text { Solicitar em caso de paciente } \\
\text { Rh negativo e pai Rh positivo ou } \\
\text { desconhecido }\end{array}$ \\
\hline $\begin{array}{l}\text { Citopatológico de colo do útero } \\
\text { (CP) }\end{array}$ & Sim & $\begin{array}{l}\text { Repetir e encaminhar para col- } \\
\text { poscopia (e, se necessário, bióp- } \\
\text { sia) em caso de resultado alterado } \\
\text { (ASCUS ou NIC) }{ }^{1}\end{array}$ & \\
\hline $\begin{array}{l}\text { Urina tipo } 1 \text { ou exame sumário } \\
\text { de urina }\end{array}$ & Sim & Ao redor de 30 semanas & \\
\hline Urocultura & Sim & 30 semanas & \\
\hline Glicemia de jejum & Sim & Após 20 semanas $^{1}$ & \\
\hline Provas de função hepática & Sim & $\begin{array}{l}\text { Na primeira consulta com } \\
\text { repetição mensal ou a cada dois } \\
\text { meses }\end{array}$ & $\begin{array}{l}\text { Em caso de uso de nevirapina, } \\
\text { deve-se realizar o controle quin- } \\
\text { zenal nas primeiras } 18 \text { semanas. } \\
\text { Após esse período, o controle } \\
\text { deve ser mensal }\end{array}$ \\
\hline Teste de tolerância à glicose 75 g & $\operatorname{Sim}$ & $\begin{array}{l}\text { Realizar após } 20 \text { semanas se a } \\
\text { glicemia de jejum } \geq 85 \mathrm{mg} / \mathrm{dl}\end{array}$ & \\
\hline VDRL & $\operatorname{Sim}$ & $\begin{array}{l}30 \text { semanas e na admissão } \\
\text { para o parto }\end{array}$ & \\
\hline Sorologia para rubéola & Não & $\begin{array}{l}\text { O Ministério da Saúde não estabe- } \\
\text { lece de rotina }^{1}\end{array}$ & \\
\hline $\mathrm{HBsAg}$ & Sim & Na primeira consulta & $\begin{array}{l}\text { Imunizar em caso de resultado } \\
\text { negativo }\end{array}$ \\
\hline Anti-HCV & Sim & Na primeira consullta & \\
\hline Anti-HAV & Sim & Na primeira consulta & $\begin{array}{l}\text { Imunizar em caso de resultado } \\
\text { negativo em gestantes coinfecta- } \\
\text { das com HCV }\end{array}$ \\
\hline
\end{tabular}

Fonte: Ministério da Saúde, 2010. 
Para isso, é necessário detectar as dificuldades de compreensão e outros obstáculos à adesão ao tratamento, garantindo o acesso da gestante à informação adequada. A tabela 2 demonstra as recomendações para o início da terapia antirretroviral. ${ }^{8,12}$

\section{Definição de via de parto no pré-natal}

A definição da via de parto deverá ser baseada no resultado da carga viral materna, realizada a partir da $34^{a}$ semana, em associação com a avaliação obstétrica.

Os estudos realizados até agora não demonstraram diferenças nas taxas de transmissão vertical ao se comparar cesariana eletiva e parto vaginal na prevenção da transmissão do HIV, quando a CV é inferior a 1.000 cópias $/ \mathrm{ml}$ em gestantes que estão em uso de esquema antirretroviral combinado. ${ }^{13}$

Cesariana eletiva, com o fim de reduzir a transmissão vertical do HIV, está indicada para as gestantes que, no final da gestação (após 34 semanas) apresentem carga viral desconhecida ou superior a 1.000 cópias $/ \mathrm{ml}^{14}$

Quando a CV for inferior a 1.000 cópias $/ \mathrm{ml}$, a via de parto será definida por critérios exclusivamente

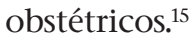

\section{Profilaxia da transmissão vertical do HIV no parto}

Todas as gestantes, independentemente do tipo de parto, devem receber AZT intravenoso (IV) desde o início do trabalho de parto ou pelo menos três horas antes da cesárea eletiva, a ser mantido até o clampeamento do cordão umbilical, segundo as doses preconizadas. Durante o trabalho de parto, ou no dia da cesárea programada, manter os medicamentos antirretrovirais (ARV) orais utilizados pela gestante, nos seus horários habituais, independentemente do jejum, ingeridos com pequena quantidade de água, inclusive durante o período de infusão venosa da zidovudina (AZT). A única droga que deve ser suspensa até 12 horas antes do início do AZT IV é a d4T (estavudina). ${ }^{8}$

\section{Esquema posológico da zidovudina injetável}

A apresentação comercial do AZT IV é de frasco ampola de $200 \mathrm{mg}$ com $20 \mathrm{ml}(10 \mathrm{mg} / \mathrm{ml})$. A parturiente deve receber zidovudina endovenosa desde o início do trabalho de parto até o clampeamento do cordão umbilical. Iniciar a infusão, em acesso venoso, individualizado, com $2 \mathrm{mg} / \mathrm{kg}$ na primeira hora, seguindo com a infusão contínua, com $1 \mathrm{mg} / \mathrm{kg} / \mathrm{hora}$, até o clampeamento do cordão umbilical. Diluir em soro glicosado a $5 \%$ e calcular gotejamento, tendo o cuidado para que a concentração não exceda $4 \mathrm{mg} / \mathrm{ml}$., 15, 16, 17

\section{Manejo da operação cesariana eletiva}

Recomenda-se:

a) confirmar a idade gestacional adequadamente, a fim de se evitar a prematuridade iatrogênica;

b) utilizar parâmetros obstétricos, como data da última menstruação correta, altura uterina, ultras-

Tabela 2. Recomendações para o início da terapia antirretroviral. Fonte: Ministério da Saúde, 2010.

\begin{tabular}{|c|c|c|}
\hline Idade gestacional & Status clínico-laboratorial da gestante & Conduta \\
\hline Após a 28aㅗ semana de gestação & $\begin{array}{l}\text { Assintomática, sem contagem } \\
\text { de } \mathrm{LT}-\mathrm{CD} 4^{+} \text {disponível }\end{array}$ & $\begin{array}{l}\text { Coletar sangue para contagem de LT-CD4 } \\
\text { e CV, iniciar imediatamente a profilaxia } \\
\text { com TARV combinada (associação de três } \\
\text { ARV) independentemente do resultado de } \\
\text { LT-CD4+ e CV }\end{array}$ \\
\hline Entre a $14^{a}$ e a $28^{a}$ semana de gestação & $\begin{array}{l}\text { Assintomática, com contagem de } \\
\text { LT-CD4 }{ }^{+} \geq 350 \text { céls. } / \mathrm{mm}^{3}\end{array}$ & $\begin{array}{l}\text { Profilaxia com TARV combinada (asso- } \\
\text { ciação de três TARV) }\end{array}$ \\
\hline Independentemente da IG & $\begin{array}{l}\text { Assintomática, com } \\
\text { LT-CD } 4 A^{+}<350 \text { céls. } / \mathrm{mm}^{3}\end{array}$ & $\begin{array}{l}\text { Tratar + quimioprofilaxia para IO (esta só } \\
\text { deve ser indicada se LT CD4 } 4^{+}<200 \text { céls./ } \\
\mathrm{mm}^{3} \text { ) }\end{array}$ \\
\hline Independentemente da IG & Sintomática** & Tratar quimioprofilaxia primária para IO \\
\hline
\end{tabular}

Legenda: $\mathrm{CV}$ = carga viral; $\mathrm{LT}=$ linfócitos $\mathrm{T} ; \mathrm{IG}$ = idade gestacional.

"Ver a seção "Como iniciar a TARV".

${ }^{* *}$ Considerar os sintomas associados à infecção pelo HIV, mesmo não definidores de AIDS. 
sonografia precoce (preferencialmente no primeiro trimestre, ou antes, da $20^{\mathrm{a}}$ semana) e realizada na $38^{\mathrm{a}}$ semana de gestação; ${ }^{17}$

c) todas as gestantes devem receber, no dia do parto, o AZT IV, dose de ataque e doses de manutenção, conforme o esquema posológico da zidovudina injetável, o qual deverá ser iniciado três horas antes do início da cesárea, período necessário para se atingir a concentração intracelular adequada do medicamento e mantido até a ligadura do cordão umbilical;

d) realizar a completa hemostasia de todos os vasos da parede abdominal e a troca das compressas ou campos secundários antes de se realizar a histerotomia, minimizando o contato posterior do recémnascido com sangue materno;

e) sempre que possível proceder ao parto empelicado (retirada do neonato mantendo as membranas corioamnióticas íntegras);

f) não realizar ordenha do cordão, ligando-o imediatamente após a retirada do recém-nascido (RN);

g) utilizar antibiótico profilático, tanto na cesárea eletiva quanto naquela de urgência: dose única endovenosa de $2 \mathrm{~g}$ de cefalotina ou cefazolina, após o clampeamento do cordão;

h) caso a gestante com indicação para a cesárea eletiva $(\mathrm{CV} \geq 1.000$ cópias $/ \mathrm{ml}$ ) inicie o trabalho de parto antes da data prevista para a cirurgia e chegue à maternidade com dilatação cervical mínima $(<3$ $\mathrm{cm}$ ), o obstetra deve iniciar a infusão intravenosa do AZT e realizar a cesárea, se possível, após três horas de infusão;

i) no caso de ruptura das membranas corioamnióticas, a cesárea não reduz a transmissão vertical, mas se um longo período de trabalho de parto está previsto, intui-se que a cesárea evita o aumento da transmissão vertical nesses casos. Também aqui a cesárea deve ser precedida do uso endovenoso de AZT pelo menos por três horas., 87,18

\section{Manejo do parto vaginal}

\section{Recomenda-se:}

a) havendo condições favoráveis para o parto vaginal e estando este indicado, iniciar o AZT intravenoso logo que a parturiente chegar ao serviço, conforme o protocolo estabelecido, e manter a infusão até a ligadura do trabalho de parto, sendo preferível a sua indução, pelo risco de ruptura artificial das membranas e aumento de risco de transmissão vertical do HIV;

b) monitorar o trabalho de parto cuidadosamente, evitando toques desnecessários e repetidos (usar o partograma);

c) evitar que as parturientes permaneçam com bolsa rota por tempo prolongado, visto que a taxa de transmissão vertical aumenta progressivamente após quatro horas de bolsa rota. O uso de fármacos que aumentam a atividade uterina não está contraindicado, mas deve ser utilizado segundo os padrões de segurança já conhecidos;

d) a amniotomia artificial deve ser evitada, a menos que extremamente necessária;

e) evitar, sempre que possível, a episiotomia. Quando necessária, o campo cirúrgico deve ser protegido por compressas embebidas em substâncias degermantes;

f) assim como na gestação, estão contraindicados todos os procedimentos invasivos durante o trabalho de parto (amniocentese, amnioscopia, amniotomia, escalpo cefálico). O parto instrumentalizado deve ser evitado, mas quando indicado, o fórceps deve ser preferido ao vácuo-extrator;

g) a ligadura do cordão umbilical deve ser imediata à expulsão do feto, não devendo ser executada, sob nenhuma hipótese, a ordenha do cordão;

h) utilizar antibiótico profilático materno: cefalotina ou cefazolina profilático em dose única de $2 \mathrm{~g}$ intravenosa. ${ }^{8}$

\section{Cuidados com o recém-nascido}

Independentemente da via de parto, faz-se necessários alguns cuidados com o RN, descritos a seguir, segundo as recomendações do MS: ${ }^{8,18-20}$

a) banhar o recém-nascido com água e sabão, imediatamente após o parto;

b) evitar traumatismos em mucosas aspirando delicadamente as vias aéreas do RN, quando necessário;

c) iniciar a primeira dose do AZT solução oral, preferencialmente, nas primeiras duas horas após o nascimento;

d) introduzir nevirapina ao esquema de quimioprofilaxia da transmissão vertical do HIV para RN de mães vivendo com HIV/AIDS que não receberam antirretrovirais na gestação;

e) realizar hemograma completo, possibilitando o monitoramento da criança no início do tratamento e após seis e 12 semanas, devido à possibilidade de ocorrência de anemia no RN em uso de zidovudina;

f) agendar, no momento da alta, para um serviço es- 
pecializado, o seguimento de crianças expostas ao HIV, assegurando o acompanhamento da criança por pediatra capacitado para o atendimento deste. tipo; ${ }^{18}$

g) alimentar o neonato com fórmula infantil. $\mathrm{O}$ aleitamento materno está contraindicado;

h) contraindicar o aleitamento cruzado ${ }^{1}$ e o uso do leite materno com "pasteurização" domiciliar; ${ }^{20}$

i) manter a criança com sua mãe em alojamento conjunto;

j) preencher e enviar a ficha de notificação da gestante $\mathrm{HIV}^{+}$e criança exposta.

Além dos cuidados descritos, é importante reforçar e estimular o vínculo mãe e bebê e oferecer todo apoio necessário para que a mulher não se sinta discriminada, principalmente, devido a não amamentação.

\section{Recomendações no puerpério}

Os riscos de transmissão do HIV através da amamentação devem ser informados às mulheres infectadas pelo HIV. Todas devem ser orientadas em como obter e preparar a fórmula infantil. ${ }^{18}$

A inibição da lactação deve ser iniciada logo após o parto, o que pode ser conseguido com medidas clínicas e/ou farmacológicas. ${ }^{21}$

As medidas clínicas mais simples consistem em realizar o enfaixamento das mamas com atadura, imediatamente após o parto, com cuidado para não causar desconforto materno. ${ }^{18}$

As medidas farmacológicas para a supressão da lactação devem considerar as contraindicações em determinadas patologias clínicas associadas.

O acompanhamento clínico, ginecológico e o da criança, até a definição de sua situação sorológica, deverá ser estimulado e monitorado. O seguimento obstétrico da mulher portadora do HIV no puerpério, salvo em situações especiais de complicações ocorridas durante o parto e puerpério imediato, é igual ao de qualquer outra mulher.

Discutir sobre a prevenção das DSTs e reinfecção pelo HIV, orientando-a quanto ao uso de preservativo em todas as relações sexuais. Informar à mulher e a seu parceiro sobre contracepção, encaminhando-os para um serviço de planejamento familiar. ${ }^{22}$

\section{Referências}

1. Brasil. Ministério da Saúde. Coordenação Nacional de DST/ AIDS. Avaliação do Projeto Nascer. 2004. [Acesso em: 21 maio 2014]. Disponível em: <http://www.aids.gov.br>
2. Brasil. Ministério da Saúde. Portaria n²104/GM, de 19 de novembro de 2002. Institui o Projeto Nascer Maternidade, onde se definem as ações de controle da transmissão vertical do HIV e da sífilis congênita no país. Diário Oficial da União 20 nov. 2002.

3. UNAIDS MHO. AIDS, epidemic update. Genebra, Dec. 2009.

4. SECRETARIA MUNICIPAL DE CAMPINAS. Campinas reduz transmissão do vírus HIV de mãe para filho para 1,2\%. [ Acesso em: dez. 2013].Disponível em: http://www.campinas.sp.gov.br/ saude/noticias/not_09_04/not_21_09_04c.htm.

5. Brasil. Secretaria Municipal de Saúde. Boletim Epidemiológico. 2002. [Acesso em: dez. 2013]. Disponível em: http://www. saude.rio.rj.gov.br/saude/pubsms/media/boletim?ר_epidemiológico-dezembro 2002.mrj.pdf.

6. Fiscus SA, Adimora AA, Schoenbach VJ, et al. Perinatal HIV infection and the effect of zidovudine therapy in transmission in rural and urban counties. JAMA 1996; 275:1483-88.

7. Wiktor SZ1, Ekpini E, Karon JM, et al. Short course oral ziduvudine for prevention of mother to child transmission of HIV. Lancet 1999; 353:781-85.

8. Brasil. Ministério da Saúde. Secretaria de Vigilância em Saúde. Recomendações para Profilaxia da Transmissão Vertical do HIV e Terapia Antirretroviral em Gestantes: manual de bolso. Brasília: Ministério da Saúde; 2010. Programa Nacional de DST e AIDS.

9. Brasil. Ministério da Saúde. Coordenação Nacional de DST e AIDS. Aconselhamento em DST, HIV e AIDS: diretrizes e procedimentos básicos. 4.ed. Brasília, DF: Ministério da Saúde; 2000.

10. Brasil. Ministério da Saúde. Coordenação Nacional de DST e AIDS. Diretrizes dos Centros de Testagem e Aconselhamento CTA. Brasília: Ministério da Saúde; 2000.

11. Conselho Federal de Medicina (Brasil). Resolução $n^{\circ} 1.665$, de 7 de maio de 2003. Dispõe sobre a responsabilidade ética das instituições e profissionais médicos na prevenção, controle e tratamento dos pacientes portadores do vírus da SIDA (AIDS) e soropositivos. [Acesso em: 14 jun. 2014]. Disponível em: http:// www.abmes.org.br/Legislacao/

12. Brasil. Ministério da Saúde. Secretaria de Vigilância em Saúde. Departamento de DST, AIDS e Hepatites virais. Protocolo Clínico e Diretrizes Terapêuticas para Manejo da Infecção pelo HIV em Adultos. Brasília; 2013.

13. Read J. Mode of delivery and vertical transmission of HIV 1: a meta-análise from fifteen prospective cohort studies (The International Perinatal HIV Group). 12th World AIDS Conference, Geneva, 28 June - 3 July 1998, Abstract 23603 LB.

14. Nogueira SA, Abreu T, Oliveira R, et al. Successful prevention of HIV transmission from mother to infant in Brazil using a multidisciplinary team approach. Braz J Infect Dis. 2001 Apr; 5(2):78-86.

15. Ioannidis JP, Abrams EJ, Ammann A, et al. Perinatal Transmission of Human imunodeficiency Virus Type 1 by Pregnant Women with RNA Virus Loads $<1000$ Copies/ml. J Infect Dis. 2001 Feb 15;183(4):539-45.

16. Connor EM, Sperling RS, Gelber R, et al. Reduction of maternal-infant transmission of human immunodeficiency virus type 1 with zidovudine treatment. N engl J Med, 1994, 331(18):1173-1180.

17. Centers for Disease Control and Prevention: Administration of zidovudine during late pregnancy and delivery to prevent perinatal HIV transmission Thailand, 1996-1998. MMWR Morb Mortal Wkly Rep 1998; 47:151-54. 


\section{Artigo de revisão}

18. Kuhn L, Bobat R, Coutsoudis A, et al.Cesarean deliveries and maternal-infant HIV transmission: results from a prospective study in South Africa J Acquir Immune Defic Syndr Hum Retrovirol. 1996 Apr 15; 11(5):478-83.

19. Brasil. Ministério da Saúde. Guia prático de preparo de alimentos para crianças menores de 12 meses que não podem ser amamentadas. Brasília, DF: Ministério da Saúde; 2004.

20. Brasil. Ministério da Saúde. Manual normativo para profissionais de saúde de maternidades da Iniciativa Hospital Amigo da Criança - referência para mulheres HIV positivas e outras que não podem amamentar. Brasília, DF: Ministério da Saúde; 2004.

21. Kochenour, NK. Lactation suppression. Clin Obstet Gynecol 1980; 23:1045.

22. Brasil. Ministério da Saúde. Guia de tratamento: recomendações para a profilaxia da transmissão materno-infantil do HIV e terapia antirretroviral em gestantes. Brasília, DF: Ministério da Saúde; 2006. 